\title{
Introduction
}

\section{Commingled Human Remains Special Issue}

\author{
Andrea Palmiotto ${ }^{\mathrm{a}, \mathrm{b}} \cdot$ Carrie Brown $^{\mathrm{c}^{*}} \cdot$ Mary Megyesi $^{\mathrm{c}}$
}

\begin{abstract}
This paper is the introduction to the special issue on commingled human remains analysis within forensic anthropology. It provides an overview of the articles in this special issue of Forensic Anthropology and the impetus behind the creation of the special issue.
\end{abstract}

KEYWORDS: forensic anthropology, commingling, postmortem identification

The analysis of commingled human remains (CHR) has become increasingly sophisticated. Commingled remains analysis in forensic anthropology was historically based on the bioarcheology of large Native American ossuaries (Finnegan 1976; Stewart 1979; Ubelaker 1978). Methods for sorting assemblages were often restricted to counting the number of elements by side, articulations, sex, and age. While these attributes are still crucial to the process of evaluating commingled remains, current forensic anthropological practice has expanded into new technologies and innovative software approaches.

The situations in which commingling can occur in modern forensic anthropology practice are varied and include mass or natural disasters such as aircraft crashes, earthquakes, and fires; humanitarian and human rights crises; and past military conflicts. These diverse situations, combined with the goal of individual identification, have pushed practitioners to create new methods, use technological innovations, and employ novel solutions to what is ultimately a very old osteological problem. And yet, while this is an old problem to osteologists, Ubelaker (2014) reminds us that commingling has only recently been tackled by forensic anthropologists.

The articles in this issue highlight many current advances in commingled assemblage examination and are expanded from a poster session titled "Science Matters: Challenges

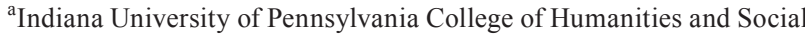
Sciences-Anthropology, Indiana, PA 15705, USA

${ }^{b}$ Defense POW/MIA Accounting Agency, Joint Base Pearl HarborHickam, Hawai'i 96853, USA

${ }^{c}$ Defense POW/MIA Accounting Agency—Laboratory, Offutt AFB, NE 68113, USA

*Correspondence to: Carrie Brown, Defense POW/MIA Accounting Agency_Laboratory, 106 Peacekeeper Dr., Bldg. 301, Offutt AFB, NE 68113, USA
}

with Effecting Individual Identifications from Commingled Assemblages" organized for the 70th annual meeting of the American Academy of Forensic Sciences in Seattle, Washington, in February 2018. They present a subset of some of the challenges facing CHR analysis, such as poorly documented or missing historical contexts, incomplete remains, or poor condition of remains. While many of the articles included in this special issue focus on the issues surrounding the sorting and identification of individuals lost in past military conflicts, the systematic approaches, methods, and new technology employed are applicable to any commingled situation. Developing and fostering new methods is integral to the future development of the field.

The session was conceived by forensic anthropologists associated with the Defense POW/MIA Accounting Agency (DPAA), which spearheads efforts to recover and identify missing U.S. service members. The organizers, familiar with several large-scale commingled human skeletal projects at the DPAA Laboratory, wanted to emphasize different techniques devised by anthropologists both within the agency and at other institutions in order to tackle the myriad issues related to these projects.

Invited participants presented on several projects, reviewed existing methods of commingling, demonstrated new approaches, and outlined unforeseen challenges to their particular situations. The final session included eleven presentations representing three institutions and eight separate projects (Proceedings 2018). We are pleased to present eight papers from that session in this special issue. Topics include research on the accuracy of visual pair-matching; a Bayesian approach to the association of skeletal remains; tests of the most accurate way to estimate the number of individuals in an assemblage; the use of biological data to inform subsequent DNA sequencing strategies; and four case reports from 
large-scale commingled projects, highlighting challenges faced and the ways in which identification is achieved.

The case reports represent projects that were organized around the tenets identified in other seminal commingled projects, such as the Korean War Project (Jin et al. 2014) and those discussed in two volumes on CHR edited by Adams and Byrd $(2008,2014)$. The Korean War Project was the first large-scale CHR project initiated at the DPAA Laboratory. Based on its success, additional large-scale commingled projects have been undertaken by the agency.

In this special issue we introduce three ongoing projects at the DPAA associated with World War II-the Cabanatuan Prison Camp Cemetery Project, the Tarawa Project, and the USS Oklahoma Identification Project. Each of these projects encompasses hundreds of commingled individuals with complex and unique historical contexts. These diverse projects present challenging situations that require creative solutions from the analytical teams.

The focus on World War II remains in this special issue (and at DPAA) is born out of the historical circumstances of World War II losses, their recovery, and subsequent processing that often resulted in commingling. All of the World War II projects at DPAA share a few bureaucratic root commonalities in how the remains were initially analyzed (Snow 1948; Steere \& Boardman 1957; Trotter 1949). A brief outline of this common history offers some perspective on these projects.

After the cessation of fighting, the Department of the Army, American Graves Registration Services (AGRS), took responsibility for the recovery and identification of individual losses under the direction of the Quartermaster General (Steere 1951). This process included disinterring remains from battlefields and temporary burial sites and delivering them to various processing stations for analysis (Steere \& Boardman 1957). For instance, Cabanatuan remains were transported to mausoleums located in Manila, while remains from Tarawa and the Oklahoma were processed at the Schofield Barracks on Oahu (Harris 2010; Harris \& Beckinbaugh 2017).

Dr. Mildred Trotter was the director of the Central Identification Laboratory on Oahu from 1948 through 1949. She oversaw identification efforts at Schofield Barracks and even visited Manila to offer guidance on the identifications of the Cabanatuan remains. Trotter lamented the difficulties in segregating U.S. service members with such similar biological profiles. The techniques available at the time to resolve commingling were somewhat limited, and Trotter and her team were able to identify duplicated elements and separate bones based on traits such as "articulation, size, color, morphology, and/or texture" (Trotter 1949). Trotter further notes that in most cases, missing skeletal elements precluded the association of continuous skeletal elements.

For the most part, however, the enormous number of unidentified remains from World War II were initially processed and recorded by AGRS personnel (Steere 1951). As a result, many of the World War II projects at DPAA are tasked with rectifying commingling caused by lack of osteological knowledge during these initial processing phases. During this post-World War II historical processing period, unidentified remains were laid to rest in American military cemeteries located around the world (Trotter 1949). These individuals were buried as "unknowns" until being disinterred by the DPAA for reanalysis. As a result of these circumstances, the three large World War II projects highlighted in this issue share some historical similarities that affect the current analysis.

The Cabanatuan Prison Camp Cemetery Project involves American POWs from the Philippines, many of whom were part of the Bataan Death March as they were transported to the POW camp on Luzon Island. The camp was occupied for over 3 years between 1942 and 1945, with thousands of individuals transferred through the camp during that period (Harris \& Beckinbaugh 2017). Individuals received inadequate food and medical care, and combined with the associated physical hardships, more than 2,700 POW deaths were reported during this time (Harris \& Beckinbaugh 2017). Individuals were buried in mass graves at the camp cemetery by other POWs; however, record keeping was difficult under such conditions.

In this issue, the Cabanatuan Project outlines the historic commingling of the remains, coupled with the past erroneous identifications that require historical context, DNA, and anthropology to resolve. In her article, Megyesi promotes an approach that includes an in-depth examination of historical records and past anthropological practices, combined with present-day analytical techniques to resolve commingling and identification issues.

The Battle of Tarawa occurred in November 1943 and resulted in more than 1,100 American and 6,000 Japanese and Korean casualties on the Republic of Kiribati, a small island in the Pacific. Casualties from the battle were buried in temporary cemeteries on the island shortly after the battle (Steere \& Boardman 1957). Later, some of these remains were disinterred and transported to the National Memorial Cemetery of the Pacific (NMCP), in Hawai' $i$, for reburial; however, less than half of the burials were located from Kiribati. Recent excavations on Kiribati have focused on locating and recovering these missing burials. As outlined by Taylor et al., analyses in 2016 revealed that in many cases, the skeletal remains of a single individual can be found both in the NMCP remains and in the recently recovered remains from Kiribati.

Upon this discovery, the Tarawa team adjusted their methods to facilitate analyses across these varied contexts. Using multiple lines of evidence, including chest radiograph comparison, dental association, pair-matching, articulation, and DNA analysis, the Tarawa team associates remains and ensures they belong to and are reunited with the correct 
individual. The article by Taylor et al. gives an overview of the challenges facing the Tarawa project team and introduces their multidisciplinary approach to resolving commingled remains for this project, and the article by Scott et al. shows how this approach is used with two specific project cases.

The goal of the USS Oklahoma Identification Project is to segregate and identify the nearly four hundred individuals missing from the battleship after the 7 December 1941 bombing of Pearl Harbor. In the 1940s the AGRS attempted to treat the associated skeletal remains as a massive group burial, with individuals desegregated and "like" elements bundled together (Harris 2010). After the mass burial was denied, the commingling was further exacerbated as analysts attempted to reassociate elements back into discrete individuals (Harris 2010). This approach proved impossible based on available technologies, and these patchwork "individuals" were buried as "unknowns" until DPAA reinitiated large-scale identification efforts in 2015. The extent of commingling was revealed when 177 elements from the first casket were sampled for mitochondrial DNA (mtDNA) analyses and 95 distinct mtDNA sequences were obtained. In this issue, Brown provides an overview of the Oklahoma project and the steps the project team takes to individually identify remains.

Since the inception of the project in 2015, the Oklahoma team has endeavored to develop new strategies and test existing methods to effectively inventory, segregate, and identify the associated elements. Three of the articles in this special issue use the Oklahoma assemblage as the basis for research to refine commingled remains analyses. Brown and Lynch discuss ways in which biological profile data is used to prioritize DNA sequencing, LeGarde tests the accuracy of visual pair-matching, and Palmiotto et al. describe the ways in which the project team codifies the approach to inventorying elements and present various methods used to estimate the number of individuals in the assemblage.

Finally, McCormick considers the implications of traditional osteometric associations, including pair-matching and articulation, when using frequentist and Bayesian statistical frameworks for commingled assemblages. In frequentist approaches, an analyst tests the null hypothesis to determine whether two elements are similar enough that they could belong to the same individual. In other words, the null hypothesis works around the concept of exclusion. In Bayesian approaches, on the other hand, an analyst attempts to determine whether two elements belong to the same individual, and thus focuses on the concept of association. McCormick tests the feasibility of Bayesian associations using measurements from 800 elements. He subsamples this data set to create commingled simulations with a Bayesian regression model. Correct matches were identified in roughly half of the 7,500 simulations.
The eight articles in this issue highlight new approaches, perspectives, and theoretical concerns when attempting to resolve large commingled assemblages. They demonstrate that complex commingling problems can be resolved with a combination of new technology and old evaluation techniques (e.g., Snow 1948; Stewart 1979; Trotter 1949). Through this issue, we introduce ways forensic anthropology has built on our foundational anthropological methods and present new technological solutions. Each commingled assemblage is unique in its history, challenges, and context. While no single approach is universally applicable, we hope the cases and situations we present here offer strategies for resolution for all the varied casework forensic anthropologists encounter.

Regardless of the historical context — battlefields, human rights investigations, mass disasters, cremation, and so forth-identification and resolution for the families and their communities are the driving force behind these scientific endeavors and are, at heart, the meaning and importance behind this work. Wagner concludes this special issue by summarizing these case studies and research papers with a reminder of the human element and personal perspectives that accompany these projects. As scientists, we must focus on objective methods and standardization for accurate individuation and segregation; however, we must also recognize and acknowledge the significance of this work to those still living.

\section{Acknowledgments}

Thank you to all of the symposium participants and authors of the enclosed articles. Thanks also to Dr. Aelwen Wetherby, who provided helpful feedback on historical citations, and to the anonymous peer reviewer, who provided comments on this introduction. The views expressed herein are those of the authors and do not represent those of the Defense POW/MIA Accounting Agency, Department of Defense, or the United States government.

\section{References}

Adams BJ, Byrd JE, eds. Recovery, Analysis, and Identification of Commingled Human Remains. Totowa, NJ: Humana Press; 2008.

Adams BJ, Byrd JE, eds. Commingled Human Remains: Methods in Recovery, Analysis, and Identification. San Diego: Academic Press; 2014.

Finnegan M. Walnut Creek massacre: Identification and analysis. American Journal of Physical Anthropology 1976;45(3): 737-742.

Harris H. History of the sinking of USS Oklahoma and subsequent attempts to recover and identify her crew. Available at: http:// www.public.navy.mil/bupers-npc/support/casualty/Docume nts/POW\%20MIA/USS\%20OKLAHOMA\%20(BB-37).pdf. Created March 1, 2010. Updated May 4, 2015. Accessed June 1, 2018. 
Harris H, Beckinbaugh L. Historical report: U.S. casualties and burials at Cabanatuan POW camp \#1. Available at: https:// www.dpaa.mil/Portals/85/Documents/Reports/U.S.Casu alties_Burials_Cabanatuan_POWCamp1.pdf?ver=2017-05 -08-162357-013. Created May 9, 2017. Accessed April 8, 2019.

Jin J, Burch AL, LeGarde CB, Okrutney E. The Korea 208: A largescale commingling case of American remains from the Korean War. In: Adams BJ, Byrd JE, eds. Commingled Human Remains: Methods in Recovery, Analysis, and Identification. San Diego: Academic Press; 2014:407-424.

Proceedings of the 70th Annual Meeting of the American Academy of Forensic Sciences, February 19-24, 2018; Seattle, WA.

Snow CE. The identification of the unknown war dead. American Journal of Physical Anthropology 1948;6:323-328.

Steere E. The graves registration service in World War II. QMC Historical Studies No. 21. U.S. Government Printing Office, Washington, DC; 1951.
Steere E, Boardman TM. Final disposition of World War II dead 1945-51. U.S. Army, Quartermaster Corps, QMC Historical Studies, Series II No. 4. Historical Branch Office of the Quartermaster General, Washington, DC; 1957.

Stewart TD. Essentials of Forensic Anthropology. Springfield, IL: Charles C. Thomas; 1979.

Trotter M. Operations at central identification laboratory. Women in Health Sciences: Bernard Becker Medical Library Digital Collection. Available at: http://beckerexhibits.wustl.edu/mowi hsp/words/TrotterReport.htm. Created 1949. Accessed March 19, 2019.

Ubelaker DH. Human Skeletal Remains: Excavation, Analysis, Interpretation. Taraxacum, Washington, DC: Taraxacum; 1978.

Ubelaker DH. Commingling analysis: Historical and methodological perspectives. In: Adams BJ, Byrd JE, eds. Commingled Human Remains: Methods in Recovery, Analysis, and Identification. San Diego: Academic Press; 2014:1-6. 